\title{
Literatura e Psicanálise: A mulher sem pecado, de Nelson Rodrigues
}

Letícia Malard

Universidade Federal de Minas Gerais

Em homenagem ao centenário de Nelson Rodrigues (1912-2012).

Resumo: Evocações de estudos entrecruzados de literatura e psicanálise na Faculdade de Letras da Universidade Federal de Minas Gerais nas décadas de 1970/80, seguidas da análise do texto da primeira peça teatral do brasileiro Nelson Rodrigues, agenciando questóes teóricas de trabalhos do psicanalista João Francisco Neves voltados para a psicanálise do casal e da familia.

Palavras-chave: Psicanálise, Literatura, Teatro.

1. Palestra apresentada no ciclo de estudos "Mal-Estar e Subjetividade" - sessão "Psicanálise e Literatura", realizado no Phorusi.p. - Instituto de Psicanálise, Belo Horizonte-MG, em 20 de setembro de 2012, e coordenada pelo médico-psicanalista Rogério Vieira Caldeira.

2. Professora Emérita da Faculdade de Letras da Universidade Federal de Minas Gerais. 


\section{Freud e os estudos sobre literatura e artes}

Quando se reporta ao Freud propulsor dos estudos aproximativos entre psicanálise e literatura, convém lembrar:

a) do ponto de vista teórico-analítico, ele não tinha interesse pela estética, pelo belo propriamente dito, mas pela criação, pelo conteúdo da obra literária ou da obra de arte e pela vida do criador. ${ }^{3}$ É claro que, considerando o inventor da psicanálise como sujeito cultíssimo, intuitivo e sensível, sempre manifestou admiração pela literatura e pela arte;

b) nesse terreno, os temas preferidos de Freud eram os mais antigos - todavia, sem exclusividade - porque estes demonstram suas teorizações sobre a atemporalidade do inconsciente, como é o caso do incesto e do parricídio, derivados da categoria "castração". Ele escreveu sobre a tragédia de Édipo, mas também sobre alguns escritores, entre eles Shakespeare e Jensen. Analisou a figura paterna em Dostoievski e apontou a repetição enquanto pulsão de morte na epopeia Jerusalém libertada, de Torquato Tasso;

c) nas relações entre o sonho e o ato criativo, quando se analisa um texto literário vê-se que a imaginação tem comportamento similar ao do sonho, mas o que o texto fala não é da ordem do sonho em si, mas do inconsciente;

d) Freud também não se debruçava sobre as questões formais da arte e da literatura. Disse que as obras artísticas correspondem à satisfação imaginária dos desejos inconscientes de seus criadores, com o objetivo de despertar a simpatia, a admiração ou o reconhecimento do Outro.

\section{Estudos articulados de literatura e psicanálise entre nós: brevíssimo histórico}

No Brasil, os primeiros trabalhos articuladores desses dois saberes e que tiveram alguma repercussão apareceram nas décadas de 1940-50. Eram escritos pobres de fundamentação teórica, que se enquadravam melhor na área da psicologia, numa época em que a produção literária era focalizada sob a ótica impressionista ou histórico-biográfica. Surgem, então, no cenário carioca, os livros

3. Cf. ROUDINESCO. Freud et la question de l'esthétique. In: L'Inconscient et ses lettres, p. 25-61. 
Machado de Assis: (a megalomania) e Graciliano Ramos: ensaio crítico-psíquico, de Hélcio Pereira da Silva, que foram bem recebidos como novidade. Houve críticos que mencionaram neles a presença inovadora da psicanálise, conforme se verifica nos numerosos recortes críticos, no final dos volumes.

Graciliano não gostou de se ver analisado daquela forma, atribuindose a infelicidade de suas personagens à infância do autor, desamparada porque sem o carinho dos pais. Encontrando-se casualmente com Pereira da Silva, este the perguntou se havia gostado do livro. Graciliano respondeu: - Meu filho, nós somos dois fodidos.

Contudo, a explosão dos estudos psicanalíticos em literatura ocorreu na década de 1970 - e falamos especificamente da Faculdade de Letras da Universidade Federal de Minas Gerais -, quando se criou o curso de pósgraduação. Era um viés analítico que corria paralelo, com algumas intersecções, ao estruturalismo lévi-straussiano, à fenomenologia e ao marxismo. Gradativamente, o Freud "puro" ia cedendo lugar a sua releitura por Lacan, quando aqui chegou o livro de seu primeiro seminário, que incluía uma análise do conto "A carta roubada”, de Edgard A. Poe, análise que nos encantava.

Não estávamos preocupados em psicanalisar o autor - como certos trabalhos das décadas anteriores no País - nem detectar resíduos de seu inconsciente nos textos, pois nem tínhamos preparo para tal. A intenção era desvendar a lógica construtiva destes, o inconsciente das personagens, sobretudo através de categorias freudianas aliadas ao estruturalismo e à releitura que delas fazia o dr. Lacan, dentro da tese de que o inconsciente é estruturado como linguagem. Assim, "grosso modo", os conceitos freudianos de "deslocamento" e "condensação" do sonho eram transpostos para a literatura sob a roupagem do exame de metáforas, metonímias e outros recursos retóricos.

Enfrentavam-se grandes dificuldades na efetivação de tais estudos, ou seja: professores de literatura sem experiência de psicanálise, psicanalistas

4. RAMOS. Graciliano: retrato fragmentado, p. 120.

5. O que estou denominando de "Freud puro" tem a ver com o seminário que apresentei no concurso para professor titular (1984), sobre a interdição do incesto em Helena, de Machado de Assis, cuja fundamentação teórica básica era o ensaio freudiano "Totem e tabu". O seminário foi publicado primeiramente em MALARD. Ensino e literatura no $2^{\circ}$ grau: problemas \& perspectivas, p. 78-91. Na mesma linha freudiana situou-se o texto de MIRANDA. A trama da denegação na Gradiva, de Jensen (1988), publicado em 1992. 
que nos socorriam sem experiência teórica de literatura. Apesar de ser moda, poucos docentes das Letras faziam psicanálise, que era cara, rara, e até mesmo estigmatizada por estas bandas, isto é: dizia-se que, quem frequentava psicanalista, "era doido ou candidato a". E muitos dos que a enfrentavam pessoas sadias procurando amenizar suas angústias - eram aconselhados a não estudar Freud e periferia, para evitar racionalizações e resistências durante esse doloroso procedimento terapêutico. ${ }^{6}$

Dos anos 90 em diante, as coisas mudaram. Os estudos se fortaleceram, Jacques Lacan continuava a subsidiá-los teoricamente de modo cada vez mais aprofundado, com a publicação de seus novos seminários. A linha de pesquisa "Literatura e Psicanálise" recrudescia, seu respectivo núcleo de estudos angariava adeptos. Professores de formação exclusiva em Letras realizaram estudos formais de psicanálise, e psicanalistas fizeram pós-graduação em literatura.

6. Nas décadas de 70-80, de nossas bibliografias das relações entre literatura e psicanálise, além dos primeiros escritos de Lacan e de todos os textos então disponíveis de Barthes, figuravam, principalmente: BELLEMIN-NOËL. Psicanálise e literatura e Vers l'inconscient du texte; CARDOSO et al. Os sentidos da paixão; CLANCIER. Psychanalyse et critique littéraire; DELEUZE. Lógica do sentido; DELEUZE e GUATTARI. Kafka: por uma literatura menor; DERRIDA. El concepto de verdad en Lacan; ENSAIOS DE PSICANÁLISE, 1; FELMAN. La folie et la chose littéraire; FREUD. La interpretación de los sueños, 1898-9 [1900], p. 343-720; Los sueños, 1900 [1901], p. 721-752; Una premonición onírica cumplida, 1899 [1941], p. 753-754; Psicopatología de la vida cotidiana (Caso Dora),1900-1901 [1901], p. 755-931; El chiste y su relación con lo inconsciente, 1905, p. 1029-1167 in Obras completas, t. 1. El delirio y los sueños en "La Gradiva", de W. Jensen, 1906 [1907], p. 1285-1336; Totem y tabu, 1912-3, p. 1745-1850; El tema de la elección de um cofrecillo, 1913, p. 1868-1875; El "Moisés" de Miguel Ángel, 1913 [1914], p. 18761894; Parte II: Los sueños, 1915-6 [1916], p. 2168-2272, in Obras completas, t. 2. Más allá del principio del placer, 1919-1920 [1920], p. 2507-2541. El porvenir de una ilusión, 1927, p. 2961-2992; El malestar en la cultura, 1929 [1930], p. 3017-3067, in Obras completas, t. 3; GARCIA. Sobre a abjeção. Boletim do Centro de Estudos Portugueses, p. 76-84; GIRARD. La violence et le sacré; KRISTEVA. Histórias de amor; Folle vérité; Polylogue; Pouvoirs de l'horreur; LAPLANCHE e PONTALIS. Vocabulário da psicanálise; LEMAIRE. Jacques Lacan: uma introdução; MANNONI. Chaves para o imaginário; RANK. Don Juan et le double. Études psychanalytiques; ROUDINESCO. L'inconscient et ses lettres e Un discours au réel.

7. Um bom exemplo do trabalho que vem sendo implementado no século XXI é o número 12 da revista Aletria, do Programa de Pós-Graduação em Estudos Literários da Universidade Federal de Minas Gerais, especial sobre o assunto. 
Resta chamar a atenção para as profundas diferenças entre o trabalho do psicanalista - que analisa um paciente, um casal ou uma família - e o do analista literário - que lida com um ou mais textos. O primeiro - escuta, analisa e interpreta, e não transmite a nenhum paciente a totalidade de sua análise e interpretação, sob pena de desestabilizar seu objetivo, quer dizer, a melhora ou a cura. É claro que não me refiro às apresentações de caso em sessões de estudo do psicanalista com seus pares. O segundo - é "obrigado" a divulgar sua análise e interpretação do texto, quer com a finalidade do ensino da literatura, da pesquisa ou da prática literária, quer com a meta de esclarecer o texto.

\section{A mulher sem pecado}

A peça, passada na atualidade (1940-41), é encenada apenas numa sala de jantar, por onde se movimenta todo o tempo o protagonista Olegário, numa cadeira de rodas. Sua obsessão é saber se a esposa Lídia o trai ou não; portanto, se ela é uma mulher com ou sem pecado, ele torcendo conscientemente para que não seja pecadora. Em busca da resposta, Olegário não se limita a atormentá-la com essa ideia, como também paga aos serviçais - o motorista Umberto e a doméstica Inézia - para vigiá-la, e convoca Gomide, empregado de sua empresa, com o fim de desvendar o passado da mulher.

Na mesma casa moram Aninha, mãe de Olegário, marcada pelo autor como "doida pacífica"; a mãe de Lídia, D. Márcia, ex-lavadeira, e Maurício, irmão de criação de Lídia. No plano do suprarreal, aparecem no palco vozes de personagens ausentes e dois fantasmas: Menina, que é Lídia aos dez anos e que nada fala, e a falecida primeira mulher de Olegário, com quem ele troca poucas palavras. ${ }^{8}$ No fim do último ato, Lídia foge com o motorista, sabe-se que Olegário se fingia de paralítico e, ao ser informado da fuga, aponta um revólver para sua cabeça. Nessa primeira peça já se destacam vários elementos que irão caracterizar o futuro teatro de Nelson e que não serão tratados aqui, por uma questão de espaço.

8. Em apresentações posteriores à estreia, Nelson retirou esses fantasmas. Não conhecemos registro dos motivos. 
Analisar uma obra teatral apresenta alguns problemas, porque o teatro é um gênero composto de texto mais representação e/ou performance. ${ }^{9}$ Estas supõem atores de carne e osso, diretor e seus auxiliares, cenário, figurino, iluminação, etc. Em tempos passados, o texto escrito pelo teatrólogo e suas respectivas marcações eram seguidos bem de perto pelos envolvidos na representação. Também não era incomum o autor monitorar a montagem e ensaios da peça, se havia a possibilidade. Quando o ator saía do texto, esquecia-o, o ponto falhava, ou, mais raramente, de propósito alterava palavras e frases, ele o fazia por "genialidade". Nos dias atuais, o diretor e seu staff - os atores, menos - atingiram a uma grande independência criadora: a bel-prazer, muitos inventam, inovam, alteram, maquiam, adaptam, melhoram (ou pioram) o legado do autor. Tornam-se autênticos copartícipes da peça, em todos os seus níveis, não raro polemizando com o autor, quando este está próximo. Ações similares são vistas nas chamadas "traduções criativas": ao traduzir um texto, muitas vezes o tradutor produz um outro texto que simplesmente dialoga com o original.

Para os efeitos deste trabalho, estamos considerando A mulher sem pecado apenas enquanto texto. Primeiro, porque não conseguimos localizar filme da peça inteira - da peça representada e não filmes nela inspirados para tornar possível articulações adequadas entre texto e representação ou performance. Segundo, porque queremos extrair da peça algumas questões originais e exclusivas trabalhadas por Nelson Rodrigues, à luz da psicanálise.

Trata-se da primeira das dezessete peças do autor, escrita em meados de 1941, aos 29 anos, e estreada em dezembro de 1942, tendo sido um retumbante fracasso. Na biografia de Nelson, Rui Castro nos transmite informações muito sumárias sobre os episódios que envolviam a peça. ${ }^{10}$ Depois da estreia, o teatrólogo foi lanchar com a esposa e já pensava escrever outra obra - Vestido de noiva - em novas coordenadas. Esta, sim, constituiu-se no seu grande sucesso. O escritor decidiu escrever teatro por dinheiro. Aquela primeira peça era destinada a ser uma chanchada, gênero de maior sucesso nos anos 1930 a 1960, tanto no teatro quanto no cinema nacional, mas o autor percebeu logo

9. Uma excelente amostra de como o gênero dramático e a crítica teatral são focalizados na virada do século XX para o XXI está no n. 7 da revista Aletria, especial sobre o assunto.

10. CASTRO. O anjo pornográfico: a vida de Nelson Rodrigues, p. 137-156. 
de início que ela adquirira tonalidades dramáticas. Concluída, mandou-a para a apreciação de figuras respeitáveis, sendo Carlos Drummond de Andrade uma delas, na condição de alto funcionário do gabinete do Ministro da Educação e Cultura. O poeta achou-a "Interessante. Muito interessante". Mas ficou nisso.

Por ocasião da escrita, Nelson tinha cerca de um ano de casado, era pai recente, empregado em $O$ Globo, onde escrevia sobre esporte e óperas. Vez por outra precisava ser internado num sanatório para tratar-se de tuberculose. Também fumava muito, sofria de desnutrição e úlcera. Rui Castro retrata assim o teatro brasileiro da época:

O eixo Procópio-Jaime-Dulcina dominava o palco e a gerência. Na qualidade de astros que arrastavam as plateias, era para eles que todos os autores queriam escrever. Como empresários e donos de seus narizes, era natural que só escolhessem as peças de acordo com o seu estilo. E, como eram todos comediantes, só queriam saber de comédias. [...] Jaime Costa e Dulcina foram dois que recusaram "A mulher sem pecado". E Nelson nem chegou a tentar Procópio. ${ }^{11}$

Ainda segundo Castro, com a peça encalhada o autor apelou a um sobrinho do ditador Getúlio Vargas, que a mandou para a Comédia Brasileira, uma companhia subsidiada pelo Serviço Nacional de Teatro, órgão do governo. Assim estreou em dezembro de 42, no Teatro Carlos Gomes, do Rio, dirigida por Rodolfo Mayer, e lá ficou duas semanas. A crítica especializada atacou-a; Roberto Marinho, proprietário d'O Globo, adorou-a; o poeta Manuel Bandeira achou-a "formidável". E Álvaro Lins, um dos mais respeitados críticos literários da época, elogiou-a com entusiasmo. Dessa forma, o teatro do jornalista Nelson nascia sob o signo da polêmica e das dissenções críticas. Reconheceu-o em 1949, num depoimento para a revista do Serviço Nacional de Teatro:

Na minha primeira peça - a título de sondagem - introduzira uma defunta falante, opinante, uma meia dúzia de visões, uma personagem incumbida de não fazer nada, uns gritos sem dono. Eram algumas extravagâncias tímidas, sem maiores consequências. Mas tanto bastou para que alguns críticos me atirassem o que lhes parecia ser a suprema injúria: me compararam a Picasso, a Portinari, etc. ${ }^{12}$

11. CASTRO. O anjo pornográfico: a vida de Nelson Rodrigues, p. 151-152.

12. RODRIGUES. Teatro desagradável. Dyonisos, p. 7. 
Focalizando a análise pelo campo histórico-social externo que emoldurava a escrita da peça, chama a atenção a total ausência de qualquer episódio a ele relacionado. O mundo enfrentava a Segunda Guerra Mundial, com o ataque japonês a Pearl Harbour, repercutindo no Brasil pelo afundamento de navios nossos na costa. Aqui, descobre-se a primeira acumulação comercial de petróleo, em Candeias-BA; recebe-se a visita de Walt Disney, nos termos da política de boas relações com os Estados Unidos; começa o grande sucesso do jornalismo nacional - o Repórter Esso - e entra em vigor o Código de Processo Civil.

Não era comum no teatro omissões a respeito dos acontecimentos de entorno. Percorrendo-se as chanchadas da ordem do dia, por exemplo, tanto as teatrais quanto as cinematográficas, confirma-se que a ditadura permitia críticas cômicas a governantes. Como explicar, então, o silêncio de Nelson sobre o que acontecia no país e no mundo?

Podem-se aventar três explicações possíveis: a alienação do autor em relação ao histórico-social, nos termos de sua indiferença ou conservadorismo políticos - situação conhecida pelos contemporâneos. Nelson tornou-se politizado somente após o golpe militar de 1964, quando o filho foi preso e perseguido político. Tal distanciamento bate de frente com uma segunda explicação: Nelson retrata no teatro o fechamento em si da classe alta, encenada na peça, burguesia enclausurada em seu mundinho, pouco se importando com o que acontece extramuros, entregue que está a questões individualistas, de amor "romântico" e traição. No caso - tudo gira em torno do ciúme doentio, de um marido querer saber se é traído ou não pela esposa, acabando por levá-la a fugir com o motorista particular da família, na troca de um cadeirante rico por um saudável pobre.

A terceira explicação - a que nos parece mais adequada - se situa na ordem do entrecruzamento entre literatura e psicanálise. Em 1936, numa crítica em $O$ Globo à ópera Esmeralda, de Carlos de Mesquita, Nelson sugere a este que saia do passado e dê um pulo à janela, que "procure adquirir uma certa cultura freudiana". ${ }^{13}$ Pode-se supor que o jornalista já tivesse lido algo de ou sobre Freud. Naquele ano, informa Salim, aqui chegou a Dra. Adelheid Koch (1896-1980), primeira psicanalista com formação reconhecida pela Associação

13. CASTRO. O anjo pornográfico: a vida de Nelson Rodrigues, p. 141. Acrescente-se que as primeiras traduções da obra de Freud no Brasil datam de quatro anos antes, pela Editora Guanabara. 
Internacional de Psicanálise - IPA - a atuar na América Latina e a exercer a análise didática. ${ }^{14}$ Lembre-se que o pai de Nelson tinha sido dono de jornal em que o filho trabalhou e, naqueles anos, Nelson atuava em um dos mais importantes diários do país, O Globo. Assim, faz sentido dizer que a ausência do campo real externo na peça, campo esse que o jornalista bem conhecia, pode ser lida como um indício de demonstração da atemporalidade do inconsciente, limitando-se ao drama de Olegário. O autor tematizava a traição como categoria psicanalítica do humano, divisando-a, segundo suas próprias palavras, como "uma repetição exasperante".

Com efeito. Olegário mantém o mesmo assunto nas conversações. Sua mãe nunca fala, sempre recusa o alimento e não para de enrolar e desenrolar no dedo um pedaço de pano. O fantasma da Lídia criança aparece em momentos cruciais. A Lídia adulta nada faz além de reclamar das desconfianças do marido. Assim, na peça são apresentados fragmentos de discursos que remetem a situações que somente quem tinha um conhecimento mínimo de psicanálise poderia agenciar. No plano do imaginário, aparece Lídia aos dez anos de idade, constantemente silenciosa e posta, na primeira cena, sentada num degrau de escada, vestida, mas com as mãos cruzadas sobre o sexo. Simbolicamente, Olegário deseja-a no interdito (é uma criança), mas a bem da verdade está-se diante de uma regressão, ou seja, atesta-se o desejo atemporal do protagonista pela mulher com quem está casado. Aparece, também, no desenrolar da peça, a falecida primeira mulher de Olegário, acusando-o de farsante.

No artigo "Teatro desagradável", já mencionado, Rodrigues comenta sobre suas peças pelo viés da desagradabilidade, mas não as vincula a questões de psicanálise. A repetição, no caso, aponta para a obsessão de Olegário em saber se é ou não traído. O texto freudiano "Más allá del principio del placer" (1920) trabalha a repetição sob diferentes óticas, relacionando-a à pulsão de morte. Assim, ao saber-se vítima de traição, o protagonista "encosta o revólver na fronte" e então cai o pano.

Dessa feita, pode-se afirmar que o trabalho com o real, o imaginário e o simbólico - para evocar a famosa trilogia lacaniana - nunca tinha sido levado ao palco no Brasil. Rodrigues foi o pioneiro e aperfeiçoou esse trabalho em peças que se sucederam.

14. SALIM. A história da psicanálise no Brasil e em Minas Gerais, p. 7. 
A mulher sem pecado, classificada por Magaldi como peça psicológica na organização do teatro completo de Rodrigues, se constitui numa história de família. ${ }^{15}$ O título, prioritariamente, é um aposto de Lídia, no universo consciente desejante do marido, e é evocada por este na inocência dos dez anos. Porém, com um corpo que excita, a garota protege os órgãos sexuais: uma mulher-criança, sem pecado. O título pode remeter também à mãe do protagonista, que é "doida pacífica" e, portanto, não pode ser responsabilizada por seus "pensamentos, palavras e obras". Numa terceira hipótese, o título vai apontar para a sogra Márcia, que, guardiã da moral, mesmo sendo acusada pelo genro de ter trocado a filha por dinheiro, reclama dele a ida sorrateira da empregada ao quarto do motorista. Inézia também seria uma não pecadora, pois, segundo o mentiroso Umberto, não chegou a pecar porque, ao procurá-lo em seu quarto, ao constatar ser ele impotente, recuou transtornada.

Em qualquer hipótese, no título transparece a conotação religiosa, não só num viés sexual psicanalítico de culpabilidade, mas também chistoso, pois, no final, Lídia revela-se uma mulher pecadora/pegadora, estando predestinada a isso. Da mesma forma, a empregada, visitante do quarto do motorista - o qual, para despistar, mentira ao patrão sobre sua impotência -, e a ex-lavadeira Márcia - que parece carregar a culpa de ter vendido a filha para o casamento. Assim, as mulheres dessa família são sem/com pecado, enquadrando-se nas teias não só da atemporalidade, mas também da ambivalência do inconsciente.

O núcleo temático da peça é Olegário e a traição. Numa leitura psicanalítica, cremos que o protagonista não quer saber se é ou não traído, pois considera a traição da mulher como algo atemporal e predestinado. Se não, vejamos: a) quer saber se, no passado, havia motivo para ser traído, antes de conhecê-la; b) quer ser traído no presente, chegando ao limite de fingir-se paralítico; c) quer ser, simultaneamente, pai e filho de Lídia, mas não marido. Afinal, fingir-se de cadeirante é buscar fragilidade, cuidados, piedade; apesar de

15. MAGALDI. Introdução. In: Teatro completo de Nelson Rodrigues, v. 1: peças psicológicas, p. 7-38. Sobre o teatro rodrigueano em geral, bem como A mulher sem pecado, vejam-se: FOFONCA. O teatro de Nelson Rodrigues: pessimismo, sexualidade e desejo. eletras, v. 18, n. 18, p. 201-224; GOBATTO. A mulher sem pecado: fantasia rodrigueana; LILENBAUM. O teatro de Nelson Rodrigues: crime como redenção?; MARQUES. A comicidade da desilusão, O Globo: Prosa, p. 3; MOTTA. Nelson Rodrigues e uma poética do fragmento: o inconsciente em cena; SALEM. A família em cena: uma leitura antropológica da dramaturgia de Nelson Rodrigues. 
seus protestos, a esposa passa a chamá-lo de "meu filho" tão logo o viu paralítico; d) quer a presença e o testemunho mudo da mãe, em todos os momentos. Ela assiste a tudo, sentada no sofá e enrolando no dedo, repetidamente, o seu paninho; o filho não suporta que ela não coma, sob pena de ela morrer; e) Olegário acaba por colocar seu motorista no caminho da esposa, exatamente para propiciar a traição; f) Lídia faz parte da trama, pois escolheu para marido esse tipo de pessoa.

Contudo, a família retratada na peça não é a tradicional - pais e filhos - mas uma organização amplificada do casal sem filhos: este, mães / sogras, irmão de criação / cunhado e serviçais domésticos. Todos moram na mesma casa e representam num único cenário - a sala de jantar. E mais: aparece em cena um empregado da empresa de Olegário, convocado para investigar o que dizem do passado de sua mulher na firma.

\section{Afinal, que família é essa?}

Num ensaio do início dos anos 90 tentamos caracterizar a família literária graciliânica de Vidas secas, com fundamento em teorizações iniciais de João Francisco Neves, psicanalista especializado em terapia de família. ${ }^{17}$ Em textos mais recentes, o autor prossegue em suas investigações teóricas, referindo-se à questão da escuta psicanalítica no século XXI, insistindo na necessidade de se ultrapassarem os limites da pele do sujeito para se chegar à escuta do casal, da família e até mesmo à distância. Diz ele:

[...] propomos uma escuta alicerçada em reflexões teóricas a partir da vivência clínica para além da relação dual: [...] as questões envolvem os conflitos conjugais/familiares, onde hoje, mais do que no passado, a presença simultânea de mais de um analisante no mesmo setting se torna não só plenamente indicada como imprescindível. ${ }^{18}$

16. Os itens e) e f) são acréscimos de psicanalistas nas discussões posteriores à palestra.

17. Refiro-me a MALARD. As relações familiares em Vidas secas, de Graciliano Ramos.

18. NEVES. "Psicanálise na contemporaneidade: diversidades", p. 5. Ver também outros sete textos inéditos do autor que abordam a temática, apresentados em conferências, seminários e colóquios do Phorusi.p. - Instituto de Psicanálise, 
Considerando-se suas colocações, pergunta-se, a partir de olhares sobre $A$ mulher sem pecado:

1. Que tipo de escuta seria adequada para a recriação dessa rica família brasileira de 1940/1941, quando a peça foi escrita?

2. Será que, saindo do teatro para a vida real e para a psicanálise, a família d'A mulher sem pecado é muito diferente da atual? Caso afirmativo, em que aspectos?

3. Mesmo acreditando-se que a literatura / o teatro antecipem questões do real, como transpor a ponte da literatura para a psicanálise e vice-versa?

4. Seria possível analisar, como um todo indivisível, essa família, cujos membros e serviçais se misturam no enfoque do mesmo assunto, uma vez que estes últimos participam do grande problema familiar proposto pelo Pai, psicanaliticamente falando? Esse problema que mobiliza toda a família é: Lídia é ou não pecadora / pegadora? Afinal, os serviçais são pagos também para vigiá-la e responder à pergunta: "Lídia é ou não é uma mulher sem pecado"?

5. Lídia é pecadora / pegadora porque Olegário a induziu à traição? Caso afirmativo, então qual é o verdadeiro problema mental do protagonista?

6. Qual é a real contribuição de Nelson Rodrigues nessa peça para se estudar, do ponto de vista psicanalítico, as patologias nuclearizadas na instituição "família"?

Como diria Machado de Assis, "são questões prenhes de questões", cujos esboços de respostas ficarão para outra oportunidade.

18. ...Belo Horizonte-MG: 1. "A psicanálise entre Dionísio e Apolo"; 2. "Projeto para uma psicanálise no século XXI - terceiro extrato: psicanálise - subjetividade / intersubjetividade - terceiro esboço de uma metapsicologia"; 3. "Subjetividade / Intersubjetividade, hoje"; 4. "Variações do Inconsciente, hoje: para além da cadeia simbólica: o irrepresentável. Uma nota introdutória"; 5. "Século XXI: o que faz ou deveria fazer o analista quando faz psicanálise, hoje"; 6. "Mal-Estar / A dor de viver: sofrimento psíquico"; 7. "Mal-Estar: subjetividade e pânico". 
Literature and Psychoanalysis: A mulher sem pecado, by Nelson Rodrigues

Abstract: Evocation of interlinked studies of Literature and Psicoanalysis at the School of Letters of the Federal University of Minas Gerais in the decades of 1970/80, followed by the analysis of the text of the first play by the Brazilian playwright Nelson Rodrigues, treating theoretic questions of works by the psychoanalyst João Francisco Neves on couples and family psychoanalysis.

Keywords: Psychoanalysis, Literature, Drama.

$$
\text { Referências }
$$

ALETRIA: Revista de Estudos de Literatura, Belo Horizonte, Pós Lit - FALE/UFMG, n. 7, 2000.

ALETRIA: Revista de Estudos de Literatura, Belo Horizonte, Pós Lit - FALE/UFMG, n. 12, abr. 2005.

BARTHES, Roland. Oeuvres complètes (1977-1980). Paris: Ed. du Seuil, 1993.

BELLEMIN-NOËL, Jean. Psicanálise e literatura. São Paulo: Ed. Cultrix, 1983.

BELLEMIN-NOËL, Jean. Vers l'inconscient du texte. Paris: PUF, 1979.

CARDOSO, Sérgio et al. Os sentidos da paixão. São Paulo: Companhia das Letras, 1987. CASTRO, Ruy. O anjo pornográfico: a vida de Nelson Rodrigues. São Paulo: Companhia das Letras, 2010.

CLANCIER, Anne. Psychanalyse et critique littéraire. Toulouse: Ed. Privat, 1980.

DELEUZE, Gilles. Lógica do sentido. São Paulo: Ed. Perspectiva, Ed. da Universidade de São Paulo, 1974.

DELEUZE, Gilles; GUATTARI, Felix. Kafka: por uma literatura menor. Rio de Janeiro: Ed. Imago, 1977.

DERRIDA, Jacques. El concepto de verdad en Lacan. Buenos Aires: Homo Sapiens, 1977.

ENSAIOS DE PSICANÁLISE, Salvador-BA, ano 1, 1981.

FELMAN, Shoshana. La folie et la chose littéraire. Paris: Ed. du Seuil, 1978.

FOFONCA, Eduardo. O teatro de Nelson Rodrigues: pessimismo, sexualidade e desejo. eletras, Curitiba, v. 18, n. 18, p. 211-224, jul. 2009. Revista eletrônica.

FREUD, Sigmund. Obras completas. Madrid: Biblioteca Nueva, 1973. 3t.

GARCIA, Célio. Sobre a abjeção. Boletim do Centro de Estudos Portugueses, Belo Horizonte, Faculdade de Letras da UFMG, p. 76-84, 1982.

GIRARD, René. La violence et le sacré. Paris: Bernard Grasset, 1979. 
GOBATTO, Gilberto. A mulher sem pecado: fantasia rodrigueana. Pulsional: Revista de Psicanálise, São Paulo, ano 19, n. 186, p. 31-36, jun. 2006.

KRISTEVA, Julia. Histórias de amor: Rio de Janeiro: Paz e Terra, 1988.

KRISTEVA, Julia. Folle vérité: vérité et vraissemblance du texte psychotique. Paris: Ed. du Seuil, 1979.

KRISTEVA, Julia. Polylogue. Paris: Ed. du Seuil, 1977.

KRISTEVA, Julia. Pouvoirs de l'horreur: essai sur l'abjection. Paris: Ed. du Seuil, 1980.

LACAN, Jacques. Écrits I. Paris: Ed. du Seuil, 1966.

LACAN, Jacques. Écrits II. Paris: Ed. du Seuil, 1970.

LAPLANCHE, J.; PONTALIS, J.-B. Vocabulário da psicanálise. Lisboa: Moraes Ed., 1976.

LEMAIRE, Anika. Jacques Lacan: uma introdução. Rio de Janeiro: Ed. Campus, 1979.

LILENBAUM, Patrícia Chiganer. O teatro de Nelson Rodrigues: crime como redenção? 10 p. Disponível em < www.letras.ufmg.br/poslit/08_publicacoes.../TEXTO\%2011_jj.pdf>. Acesso em: 10 jul. 2012.

MAGALDI, Sábato. Introdução. In: MAGALDI, Sábato (Org.). Teatro completo de Nelson Rodrigues, v. 1: peças psicológicas. Rio de Janeiro: Nova Fronteira, 1981. p. 7-38.

MALARD, Letícia. Personagens machadianas no divã. In: Ensino e literatura no $2^{\circ}$ grau: problemas \& perspectivas. Porto Alegre: Mercado Aberto, 1985. p. 77-104.

MALARD, Letícia. As relações familiares em Vidas secas, de Graciliano Ramos. Brasil/ Brazil, Porto Alegre / Providence, v. 5, n. 4, p. 23-38, 1991.

MANNONI, O. Chaves para o imaginário. Petrópolis: Ed. Vozes, 1973.

MARQUES, Fernando. A comicidade da desilusão, O Globo: Prosa, Rio de Janeiro, 18 de agosto de 2012, p. 3.

MIRANDA, José Américo. A trama da denegação na Gradiva de Jensen. Belo Horizonte, NAPq / FALE / UFMG, agosto de 1992. [Cadernos de Pesquisa, n. 7.]

MOTTA, Vera Dantas de Souza. Nelson Rodrigues e uma poética do fragmento: o inconsciente em cena. Tese de doutorado. Universidade Federal da Bahia, Salvador, 2006. Disponível em: <http://www.bibliotecadigital.ufba.br/tde_arquivos/20/TDE-200607-11T123102Z-227/Publico/VeraComSeg.pdf>. Acesso em: 19 ago. 2012.

NEVES, João Francisco. A psicanálise entre Dionísio e Apolo: Conferência de abertura da IV Jornada, 2006, do Phorusi.p. - Instituto de Psicanálise. Belo Horizonte. 54p. Inédito.

NEVES, João Francisco. Projeto para uma psicanálise no século XXI - terceiro extrato: psicanálise - subjetividade / intersubjetividade - terceiro esboço de uma metapsicologia. Colóquio Nevisiano, 29 de maio de 2010, Phorusi.p. - Instituto de Psicanálise, Belo Horizonte. 51p. Inédito.

NEVES, João Francisco. Subjetividade / Intersubjetividade, hoje. Conferência de abertura da VIII Jornada, 18/19 de novembro de 2010, Phorusi.p. - Instituto de Psicanálise, Belo Horizonte. 12p. Inédito.

NEVES, João Francisco. Variações do Inconsciente, hoje: Para além da cadeia simbólica: o irrepresentável. Uma nota introdutória. Colóquio, 30 de maio de 2011. Phorusi.p. Instituto de Psicanálise, Belo Horizonte. 18p. Inédito.

NEVES, João Francisco. Século XXI: o que faz ou deveria fazer o analista quando faz psicanálise, hoje. Conferência de abertura da IX Jornada: Variações do inconsciente, hoje. 18/19 de novembro de 2011, Phorusi.p. - Instituto de Psicanálise, Belo Horizonte. 17p. 
NEVES, João Francisco. Psicanálise na contemporaneidade - diversidades, Phorusi.p. Instituto de Psicanálise, Belo Horizonte. 8p. Inédito.

NEVES, João Francisco. Mal-Estar / A dor de viver: sofrimento psíquico. Seminário "Mal-Estar e Subjetividade" - Módulo II. 28 de abril de 2012, Phorusi.p. - Instituto de Psicanálise, Belo Horizonte. 19 slides. Inédito.

NEVES, João Francisco. Mal-Estar: subjetividade e pânico. Seminário "Mal-Estar e Subjetividade - Módulo III". 30 de junho de 2012, Phorusi.p. - Instituto de Psicanálise, Belo Horizonte. 9p. Inédito.

RAMOS, Ricardo. Graciliano: retrato fragmentado. São Paulo: Ed. Siciliano, 1992.

RANK, Otto. Don Juan et le double: études psychanalytiques. Paris: Ed. Payot, 1973.

RODRIGUES, Nelson. A mulher sem pecado. In: MAGALDI, Sábato (Org.). Teatro completo de Nelson Rodrigues, v. 1, Peças psicológicas. Rio de Janeiro: Nova Fronteira, 1981. p. 41-103.

RODRIGUES, Nelson. Teatro desagradável. Dyonisos, Rio de Janeiro, n. 1, 1949, p. 4-13.

ROUDINESCO, Elisabeth. L'inconscient et ses lettres. Paris: Maison Mame, 1975.

ROUDINESCO, Elisabeth. Un discours au réel: théorie de l'inconscient et politique de la psychanalyse. Paris: Maison Mame, 1973.

SALEM, Tânia. A família em cena: uma leitura antropológica da dramaturgia de Nelson Rodrigues. 22p. Disponível em: <www.abep.nepo.unicamp.br/docs/anais/pdf/1984/ T84V01A22.pdf>. Acesso em: 3 jul. 2012.

SALIM, Sebastião Abrão. A história da Psicanálise no Brasil e em Minas Gerais. 13p. Disponível em: <febrapsi.org.br>.

SILVA, H. Pereira da. Graciliano Ramos: ensaio crítico-psíquico. 2 ed. Rio de Janeiro: G. T. L., 1954.

SIlvA, H. Pereira da. Machado de Assis: (a megalomania). 2 ed. Rio de Janeiro: Ed. Brand, s.d. 
